\title{
A case of autochthonous human Dirofilaria infection, Germany, March 2014
}

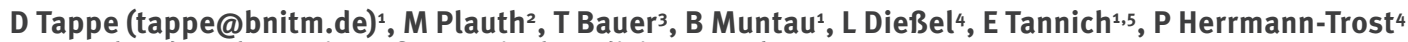

1. Bernhard Nocht Institute for Tropical Medicine, Hamburg, Germany

2. Städtisches Klinikum Dessau, Klinik für Innere Medizin, Dessau-Roßlau, Germany

3. Mund-Kiefer-Gesichtschirurgie Halle Dessau, Dessau, Germany

4. Amedes MVZ für Pathologie und Zytodiagnostik Halle/Saale, Germany

5. German Centre for Infection Research, partner site Hamburg-Luebeck-Borstel, Hamburg, Germany

Citation style for this article:

Tappe D, Plauth M, Bauer T, Muntau B, Dießel L, Tannich E, Herrmann-Trost P. A case of autochthonous human Dirofilaria infection, Germany, March 2014 . Euro Surveill. 2014;19(17): pii=20790. Available online: http://www.eurosurveillance.org/ViewArticle.aspx?Articleld=20790

Article submitted on 22 April 2014 / published on 01 May 2014

In March 2014, an infection with the nematode Dirofilaria repens was diagnosed in a German citizen in the federal state of Saxony-Anhalt. The patient had developed an itching subcutaneous nodule containing a female worm, which was identified as $D$. repens by $12 \mathrm{~S}$ ribosomal ribonucleic acid (rRNA) gene sequencing. Autochthonous human $D$. repens infections have not been described in Germany so far, but this finding is consistent with the recent detection of $D$. repens in mosquitoes from east Germany.

Here we report the clinical and laboratory findings of the first autochthonous Dirofilaria infection acquired in Germany, diagnosed in early 2014 .

\section{Case description}

A previously healthy German citizen aged in the late thirties was seen at a maxillofacial surgery centre in Dessau (federal state of Saxony-Anhalt), Germany, on 26 February 2014 , with a subcutaneous nodule on the right temple. The lesion had developed over the past four weeks and was accompanied by an itching sensation and occasional stabbing pain with increasing intensity. The patient did not report fever or any other symptoms. On examination, a discrete pea-sized skin nodule without surrounding inflammation was found, which was excised under local anaesthesia.

\section{Investigation of the cause of infection}

Histopathological examination of the excised $8 \times 4 \times 3$ $\mathrm{mm}$ nodule revealed yellowish tissue with multiple longitudinal and transverse sections through a nematode (Figure 1). The organism was surrounded by a dense inflammatory infiltrate, which contained eosinophils, macrophages, epitheloid cells, lymphocytes, and a few multinucleated giant cells. The nematode's cuticle showed external ridges suggesting a Dirofilaria infection. Internal structures, like a folded paired uterus and a digestive tract were clearly visible.
A nematode-specific $12 \mathrm{~S}$ ribosomal ribonucleic acid (rRNA) gene-polymerase chain reaction (PCR) [1] from the formalin-fixed paraffin-embedded specimen was positive. Sequence analysis of the $510 \mathrm{bp}$ amplicon (www. http://blast.ncbi.nlm.nih.gov), revealed $99 \%$ similarity with $D$. repens sequences isolated in Turkey and Italy (GenBank accession numbers: KC953031, and AJ544832, AM779773, respectively). A serum sample drawn on 17 March 2014 showed a titre of $42 \mathrm{U}$ (normal value (10) in an enzyme-linked immunosorbent assay (ELISA) using a crude Dirofilaria immitis antigen extract. Other ELISAs employing crude Ascaris lumbricoides and Strongyloides stercoralis antigens were negative. The patient was not treated with anthelminthics.

\section{FIGURE 1}

Longitudinal and transversal sections through female Dirofilaria repens nematode recovered from a patient in Germany, March 2014

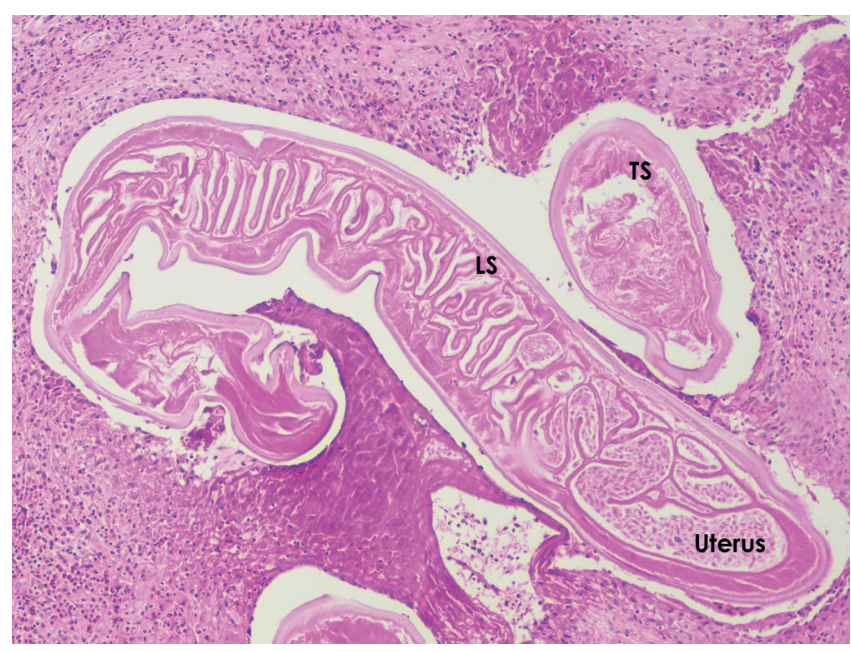

LS: longitudinal section; TS: transversal section.

Haematoxylin and eosin stain, original magnification $\times 100$.

The extensively folded uterus is clearly visible in the longitudinal section. 
Follow-up of the patient

Fourteen days after the operation, the patient was referred for further diagnostic work-up. On physical examination, cardio-pulmonary, abdominal and neurological status was normal. A chest X-ray and abdominal ultrasound revealed no pathology. Full blood count revealed $7 \%$ eosinophils (normal range $<7 \%$ ) and a total leukocyte count of $7.5 \mathrm{Gpt} / \mathrm{L}$ (normal range: 3.8-10.5). Erythrocyte sedimentation rate (ESR) and routine clinical laboratory tests were normal.

\section{Investigation of possible sources of infection}

During the last 37 years, the patient has been living in the state of Saxony-Anhalt, in a farm house in a small village close to the river Elbe. The patient owns a pet dog and several horses. Parasitological examination of blood drawn from the patient's dog was negative for microfilariae. Except for a one-day trip to Poland, in mid-December 2013, and a short vacation trip to the Czech Republic in winter 2012, the patient had not travelled elsewhere within the past five years. The patient is a passionate angler and used to catch fish in two nearby quarry ponds in the Bitterfeld region, SaxonyAnhalt. The patient recalled multiple mosquito bites during fishing sessions in September 2013, and while working on farm house fields. The whole area was affected by the floods from the nearby Elbe river in summer 2013, and many farm fields remained partially flooded for a prolonged time.

\section{Background}

D. repens is a filarial nematode of dogs and other carnivores as definitive hosts. Similar to other filarial species, microfilariae of $D$. repens are transmitted by mosquitoes, and fertile macrofilariae develop in the natural definitive host. Humans may become infected as abberant hosts and with a few exceptions, the worm remains infertile, and therefore microfilariae are not produced [2]. The incubation time in human infections is not well defined but has been estimated to range between four and eight months [3].

Clinically, a single subcutaneous nodule is most often present $[4,5]$. Local swellings with changing localisations, caused by migrating worms, may occur [6]. Only rarely, cases of organ infection have been described, affecting the lungs, genitals, breasts, or the eye $[4,5]$. Recently, a severe meningoencephalitic infection in a traveller returning from India and Sri Lanka has been described and the capacity of filariae to cause lifethreatening disease has been demonstrated [6].

Diagnosis may be achieved parasitologically, when a living and intact worm can be extracted and inspected, or histopathologically, after surgical excision of the infected tissue. As there are numerous and morphologically very similar zoonotic Dirofilaria species, molecular identification of the organism should be aimed for [6]. Eosinophilia and positive Dirofilaria serology may be present [6]. In infections affecting the skin only, surgical removal of the parasite is effective and usually no further treatment is required. In generalised infections, however, additional systemic therapy with albendazole is recommended [6].

Human Dirofilaria infections have been reported in Africa, Asia and also in Europe where dirofilariasis is an emerging zoonosis [7]. The areas in Europe where endemicity of $D$. repens has been solidly established, concern countries of the Mediterranean region [7], where the warmer climate facilitates the development of infectious larvae in mosquitoes. However, during the past decade, several sporadic autochthonous human and canine cases of dirofilariasis have been reported from countries further north in central Europe, including Austria, the Czech Republic, and Poland [8-10]. Until recently, central Europe, including Germany, was not considered a region in which $D$. repens is endemic. However, the recent finding of $D$. repens-infected dogs and mosquitoes in east Germany in the federal state of

\section{FIGURE 2}

Geographical distribution of autochthonous human and canine Dirofilaria repens infections and origin of mosquitoes testing positive for $D$. repens DNA, Germany, as of March 2014

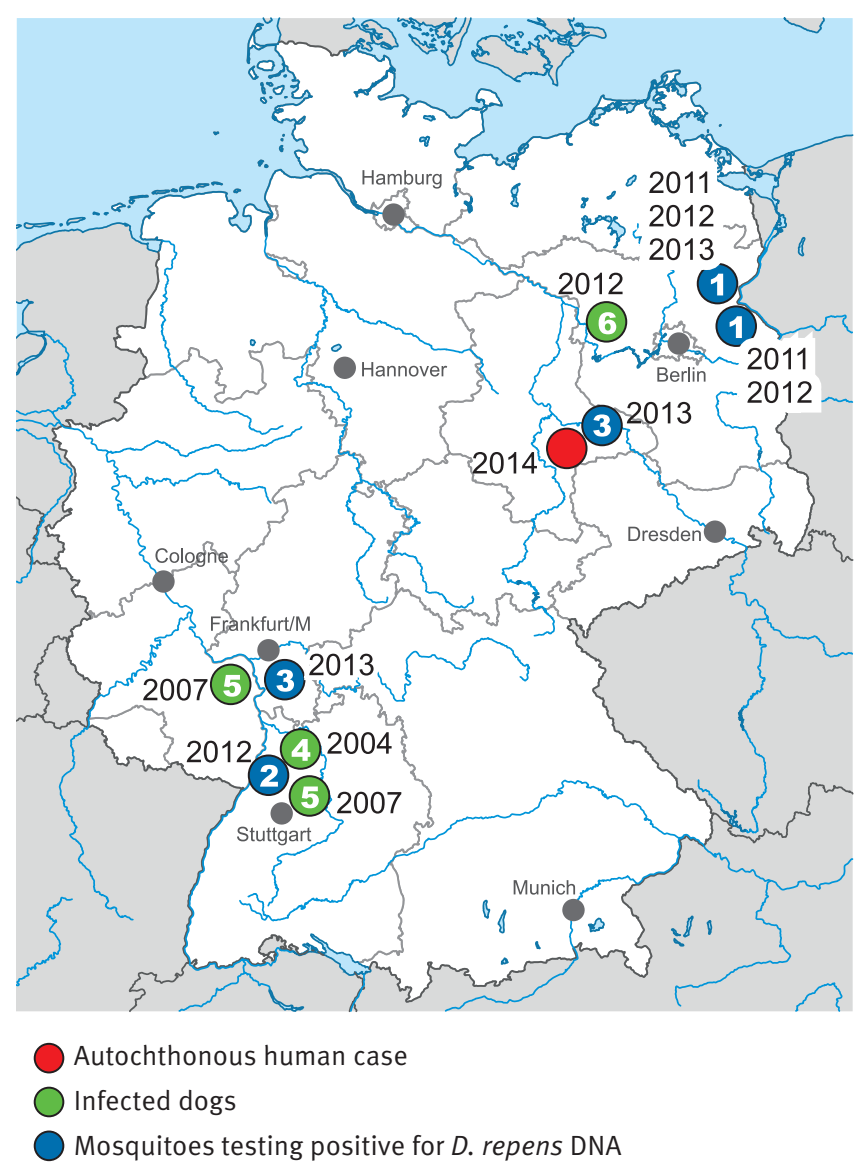

Numbers within the circles refer to references. 1: Czajka et al. 2014 [11]; 2: Kronfeld et al. 2014 [13]; 3: Tannich, unpublished observation; 4: Hermosilla et al. 2006 [14]; 5: Panchev et al. 2009 [15]; 6: Sassnau et al. 2013 [12]. The years of detection are indicated beside each coloured circle. 
Brandenburg (which is located next to Saxony-Anhalt) $[11,12]$, as well as infected mosquitoes in southwest Germany [13] suggested that stable transmission of $D$. repens is already taking place in Germany as the northernmost transmission area in Europe so far [11,12]. The present case of an autochthonous human infection in east Germany lends further support to this notion.

\section{Discussion and conclusions}

This is the first report of a laboratory-confirmed autochthonous human Dirofilaria infection in Germany. Infected mosquito populations have recently been detected in Saxony-Anhalt (data not shown), close to where the patient resides. The case highlights that shortly after the repeated detection of the parasite in local mammalophilic mosquito populations, human infections may occur (Figure 2).

The case's dog was not infected and thus not the reservoir of the worm. The geographical location where the case's infection most probably occurred was in the federal state of Saxony-Anhalt, where the patient had been affected from multiple mosquito bites on farm grounds and while fishing. The area was severely affected by the Elbe river floods, a circumstance, which may have greatly facilitated an increased transmission rate of $D$. repens. An infection of the case outside of Germany is highly unlikely as the visits to Poland ( 3 months prior to signs of infection) and the Czech Republic (over 1 year prior) were both in the wintertime with no mosquito activity. Moreover, the reported incubation period of four to eight months fits well with an infection in late summer 2013 in Germany, where, during this time, the case reported having been bitten by mosquitoes.

At present, the true burden of $D$. repens infections in Germany is unknown as data on parasite prevalence in both humans and dogs are not available. However, the data available stress the need for timely information of physicians to increase awareness for the disease, and veterinarians to implement control measures, such as treatment of infected dogs and other canines to reduce the parasite burden and thus the transmission likelihood.

Conflict of interest

None declared.

Authors' contributions

Wrote the manuscript: DT, TB, BM, ET, MP, LD, PHT; performed laboratory or epidemiological investigations: DT, BM, ET, LD, PHT; performed data analysis: DT, BM, ET, PHT.
References

1. Casiraghi M, Bain O, Guerrero R, Martin C, Pocacqua V, Gardner SL, et al. Mapping the presence of Wolbachia pipientis on the phylogeny of filarial nematodes: evidence for symbiont loss during evolution. Int J Parasitol. 2004;34(2):191-203. http://dx.doi.org/10.1016/j.ijpara.2003.10.004

2. Pampiglione $S$, Schmid $C$, Montaperto $C$. [Human dirofilariasis: discovery of a gravid female of Dirofilaria repens in a subcutaneous nodule]. Pathologica. 1992;84(1089):77-81. Italian.

3. Sassi SH, Abid L, Dhouib R, Mrad K, Bouguila H, Abbes I, et al. [Conjunctival dirofilariasis due to Dirofilaria repens. A new Tunisian case]. J Fr Ophtalmol. 2006;29(2):e5. French.

4. Pampiglione S, Rivasi F, Angeli G, Boldorini R, Incensati RM, Pastormerlo M, et al. Dirofilariasis due to Dirofilaria repens in Italy, an emergent zoonosis: report of 60 new cases. Histopathology. 2001;38(4):344-54. http://dx.doi. $\operatorname{org} / 10.1046 / j .1365-2559.2001 .01099 . x$

5. Pampiglione S, Rivasi F. Human dirofilariasis due to Dirofilaria (Nochtiella) repens: an update of world literature from 1995 to 2000. Parassitologia. 2000;42 (3-4):231-54.

6. Poppert S, Hodapp M, Krueger A, Hegasy G, Niesen WD, Kern WV, et al. Dirofilaria repens infection and concomitant meningoencephalitis. Emerg Infect Dis. 2009;15(11):1844-6. http://dx.doi.org/10.3201/eid1511.090936

7. Genchi C, Kramer LH, Rivasi F. Dirofilarial infections in Europe. Vector Borne Zoonotic Dis. 2011;11(10):1307-17. http://dx.doi. org/10.1089/vbz.2010.0247

8. Auer H, Susani M. [The first autochthonous dirofilariosis in Austria]. Wien Klin Wochenschr. 2008;120(19-20 Suppl 4):1046. German.

9. Svobodová Z, Svobodová V, Genchi C, Forejtek P. The first report of autochthonous dirofilariosis in dogs in the Czech Republic. Helminthologia. 2006;43(4):242-5. http://dx.doi. org/10.2478/s11687-006-0046-5

10. Cielecka D, Żarnowska-Prymek H, Masny A, Salamatin R, Wesotowska M, Gołąb E. Human dirofilariosis in Poland: the first autochthonous infections with Dirofilaria repens. Ann Agric Environ Med. 2012;19(3):445-50.

11. Czajka C, Becker N, Jöst H, Poppert S, Schmidt-Chanasit J, Krüger A, et al. Stable transmission of Dirofilaria repens nematodes, northern Germany. Emerg Infect Dis. 2014;20(2):328-31. http://dx.doi.org/10.3201/eid2002.131003

12. Sassnau R, Kohn M, Demeler J, Kohn B, Müller E, Krücken J, et al. Is Dirofilaria repens endemic in the Havelland district in Brandenburg, Germany? Vector Borne Zoonotic Dis. 2013;13(12):888-891. http://dx.doi.org/10.1089/vbz.2012.1293

13. Kronefeld M, Kampen H, Sassnau R, Werner D. Molecular detection of Dirofilaria immitis, Dirofilaria repens and Setaria tundra in mosquitoes from Germany. Parasit Vectors. 2014; 7:30. http://dx.doi.org/10.1186/1756-3305-7-30

14. Hermosilla C, Panchev N, Dyachenko V, Gutmann M, Bauer C. First autochthonous case of canine ocular Dirofilaria repens in Germany. Vet Rec. 2006;158(4):134-5. http://dx.doi. org/10.1136/vr.158.4.134

15. Pantchev N, Norden N, Lorentzen L, Rossi M, Rossi U, Brand $B$, et al. Current surveys on the prevalence and distribution of Dirofilaria spp. in dogs in Germany. Parasitol Res. 2009;105 Suppl 1:S63-74. http://dx.doi.org/10.1007/s00436-009-1497-7 